\title{
Corrosive-coordinate engineering to construct 2D-3D nanostructure with trace Pt as efficient bifunctional electrocatalyst for overall water splitting
}

\author{
Zhi Chen ${ }^{1}$, Dongzheng Liu ${ }^{1}$, Yuxiao $\mathrm{Gao}^{1}$, Ying Zhao ${ }^{1}$, Weiping Xiao ${ }^{2}$, Guangrui Xu1, Tianyi $\mathrm{Ma}^{3}$, \\ Zexing $\mathrm{Wu}^{1^{*}}$ and Lei Wang ${ }^{1^{*}}$
}

\begin{abstract}
The development of efficient electrocatalysts for hydrogen evolution reaction (HER) and oxygen evolution reaction (OER) with excellent catalytic performance and stability plays key roles in the commercialization of water splitting to generate hydrogen energy. Herein, a 2D-3D nanostructure composed of metal hydroxides and Prussian blue analogus (PBA) was in-situ decorated onto the NiFe foam (Pt-NiFe PBA) through a facile and scalable corrosive-coordinate approach. The specifically designed morphology favored the provision of abundant active sites, optimized the reaction pathway, and accelerated mass transport during the electrocatalytic process. Consequently, the as-synthesized Pt-NiFe PBA reached $10 \mathrm{~mA} \mathrm{~cm}{ }^{-2}$ with small overpotentials of 29 and $210 \mathrm{mV}$ in $1 \mathrm{~mol} \mathrm{~L}^{-1} \mathrm{KOH}$ deionized water for HER and OER, respectively. Remarkably, Pt-NiFe PBA required an overpotential of $21 \mathrm{mV}$ to drive $10 \mathrm{~mA} \mathrm{~cm}$ in seawater containing $1 \mathrm{~mol} \mathrm{~L}^{-1} \mathrm{KOH}$ with prominent durability. Moreover, with the as-synthesized Pt-NiFe PBA as bifunctional electrocatalyst, the Pt-NiFe PBA || $\mathrm{Pt}-\mathrm{NiFe} \mathrm{PBA}$ electrolyzer needed 1.46 and $1.48 \mathrm{~V}$ to drive $10 \mathrm{~mA} \mathrm{~cm}^{-2}$ in $1 \mathrm{~mol} \mathrm{~L}^{-1} \mathrm{KOH}$ with deionized water and $1 \mathrm{~mol} \mathrm{~L}^{-1} \mathrm{KOH}$ with seawater, respectively. Remarkably, sustainable energies were utilized to power the overall water splitting and stored as easily portable hydrogen energy.
\end{abstract}

Keywords: electrocatalytic water splitting, hydrogen evolution reaction, oxygen evolution reaction, $2 \mathrm{D}-3 \mathrm{D}$ nanostructure

\section{INTRODUCTION}

Water splitting has sparked tremendous interest owing to its sustainable, simple, and high-efficiency merits to generate highpurity $\mathrm{H}_{2}$ gas and alleviate growing environmental and energy issues [1-6]. Nevertheless, the sluggish kinetics in anodic oxygen evolution reaction (OER) $[7,8]$ and cathodic hydrogen evolution reaction (HER) limits the energy conversion efficiency [9-15], which mainly depends on the catalytic performances of electrocatalysts [16-21]. At present, noble metal Pt- and Ru/Ir-based nanomaterials are the benchmark electrocatalysts toward HER and OER [22-26]; however, the high price and scarcity hinder the practical commercialization of water splitting technology [27-30]. In general, HER and OER electrocatalysts present remarkable electrocatalytic performances in acid and alkaline media, respectively, owing to their favorable reaction kinetics $[31,32]$. Thus, the mismatched electrocatalysts in the same electrolyte also degrade the electrocatalytic activity and increase the cost accordingly. Therefore, tremendous endeavors have been devoted to efficient, earth-abundant, and bifunctional catalysts to promote electrocatalytic performance and lower the price of hydrogen energy.

Recently, two-demissional (2D) metal hydroxides have attracted extensive attention owing to their remarkable electrocatalytic activity toward OER in alkaline electrolytes [33,34]. A variety of multimetallic hydroxides have been exploited to accelerate the reaction kinetics of OER [35]. However, the small specific surface area, high electrical resistance, and limited exposed active sites hamper their electrocatalytic activities. As reported [36], the construction of hybrids by combining different catalysts is a new and promising approach to boost electrocatalytic activity. As a class of new materials, 3D metal organic frameworks (MOFs) have drawn extensive attention in energy-related fields due to their easy tunability, porosity, and high specific surface area [37,38]. On the basis of the above merits, hybridization of 2D metal hydroxides and 3D MOF into an integrated morphology will deliver remarkable electrocatalytic performances. For instance, Zhai and co-authors [39] constructed conductive MOF/layered double hydroxide (LDH) heteronanotube arrays by a solvothermal procedure followed by heat treatment; the arrays presented an extraordinary OER performance in the alkaline electrolyte at $216 \mathrm{mV}$ to deliver $50 \mathrm{~mA} \mathrm{~cm}^{-2}$ photocurrent density. In general, metal hydroxides are prepared via a high-temperature solvothermal process under high pressure [40]. Then, a facile and scalable avenue must be developed to prepare metal hydroxides for electrochemical energy conversion. Moreover, the application of the prepared electrocatalysts onto a glassy carbon electrode with Nafion polymer as the binder will block active sites, decrease electrical conductivity, and degrade the electrocatalytic performance. Decorating the prepared electrocatalysts onto self-supported current collectors, such as carbon cloth, $\mathrm{Ni}$ foam, and Cu foam,

\footnotetext{
${ }^{1}$ Key Laboratory of Eco-chemical Engineering, Taishan Scholar Advantage and Characteristic Discipline Team of Eco Chemical Process and Technology, Qingdao International Cooperation Base of Ecological Chemical industry and Intelligent Manufacturing, College of Chemistry and Molecular Engineering, Qingdao University of Science and Technology, Qingdao 266042, China

${ }^{2}$ College of Science, Nanjing Forestry University, Nanjing 210037, China

${ }^{3}$ Centre for Translational Atomaterials, Swinburne University of Technology, John Street, Hawthorn, VIC 3122, Australia

* Corresponding authors (emails: inorchemwl@126.com (Wang L); splswzx@qust.edu.cn (Wu Z))
} 
is an effective approach to address the above issues [41,42].

Herein, we in-situ constructed a 2D-3D nanostructure onto commercial NiFe foam via a facile and reliable corrosion-coordination approach. As illustrated in Scheme 1, metal hydroxide was in-situ decorated onto the NiFe foam (NIF) in the presence of $\mathrm{NaCl}$ at ambient condition via a corrosive procedure. Then, the 3D MOF was in-situ generated on the metal hydroxide template through coordination interactions between the added $\mathrm{K}_{3}\left[\mathrm{Fe}(\mathrm{CN})_{6}\right]$ and $\mathrm{Ni} / \mathrm{Fe}$ ions. Finally, a low-temperature solvothermal method was adopted to load trace Pt onto the above designed 2D-3D nanostructure. Benefiting from the specific nanostructure, abundant exposed active sites, the coupling effects of metal hydroxide and MOF, and the binder-free properties, the developed Pt-NiFe PBA (Prussian blue analogus) exhibited superior electrocatalytic activities and stability for HER, OER, and overall seawater splitting. Remarkably, sustainable energies were utilized to power the overall water splitting and stored as easily portable hydrogen energy.

\section{RESULTS AND DISCUSSION}

Scanning electron microscopy (SEM) and transmission electron microscopy (TEM) were performed to study the microstructure of the prepared electrocatalyst. Relative to the smooth surface of NIF (Fig. S1a, b), a 2D nanosheet structure was generated via a facile corrosive process (Fig. S1c, d), and a 3D cubic morphology formed onto the 2D nanosheet via the coordinate reaction with $\mathrm{K}_{3}\left[\mathrm{Fe}(\mathrm{CN})_{6}\right]$ (Fig. S1e, f), demonstrating that the 2D-3D nanostructure was synthesized successfully through corrosivecoordinate engineering. As illustrated in Fig. 1a, b, the 2D-3D morphology with abundant channels was maintained well, except for the extra wrinkles, after the low-temperature solvothermal process to load trace $\mathrm{Pt}$, which can favor mass transport and provide rich active sites during catalytic reactions. After the corrosive and coordinate procedure (Fig. S2a-c), $\mathrm{Ni}_{2}\left[\mathrm{Fe}(\mathrm{CN})_{6}\right] \cdot 0.5 \mathrm{H}_{2} \mathrm{O}$ (PDF\#46-0908), FeOOH (PDF\#08-0098), and $\mathrm{Fe}_{2} \mathrm{Ni}_{2}(\mathrm{CO})_{3} \mathrm{OH}_{8} \cdot 2 \mathrm{H}_{2} \mathrm{O}$ (PDF\#49-0188) were detected, demonstrating that the $3 \mathrm{D}$ MOF was generated onto the NIF successfully [43-45]. The 3D cubic morphology and 2D nanosheet structure were verified by TEM measurement (Fig. 1c). As shown in Fig. 1d, the interfaces (dotted red line) formed between the $2 \mathrm{D}$ and $3 \mathrm{D}$ nanostructure which could improve the electrocatalytic performance effectively by opti-

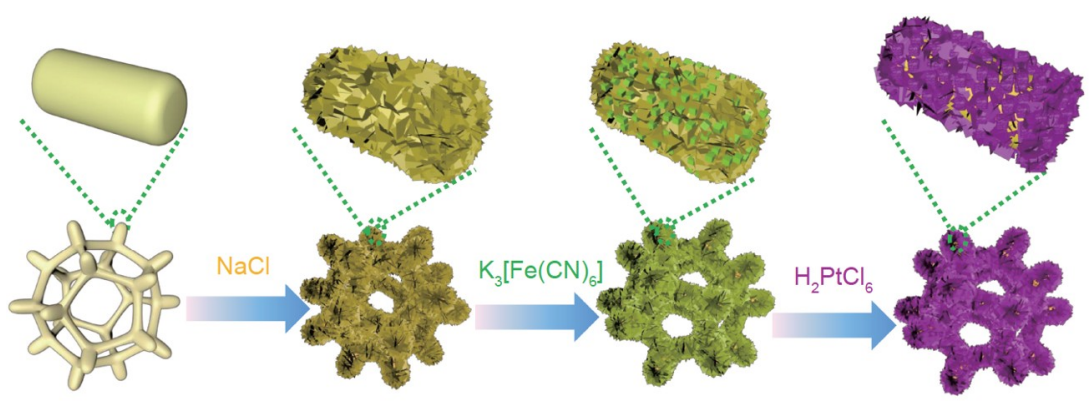

Scheme 1 Schematic of the synthesis of the 2D-3D nanostructured Pt-NiFe PBA.
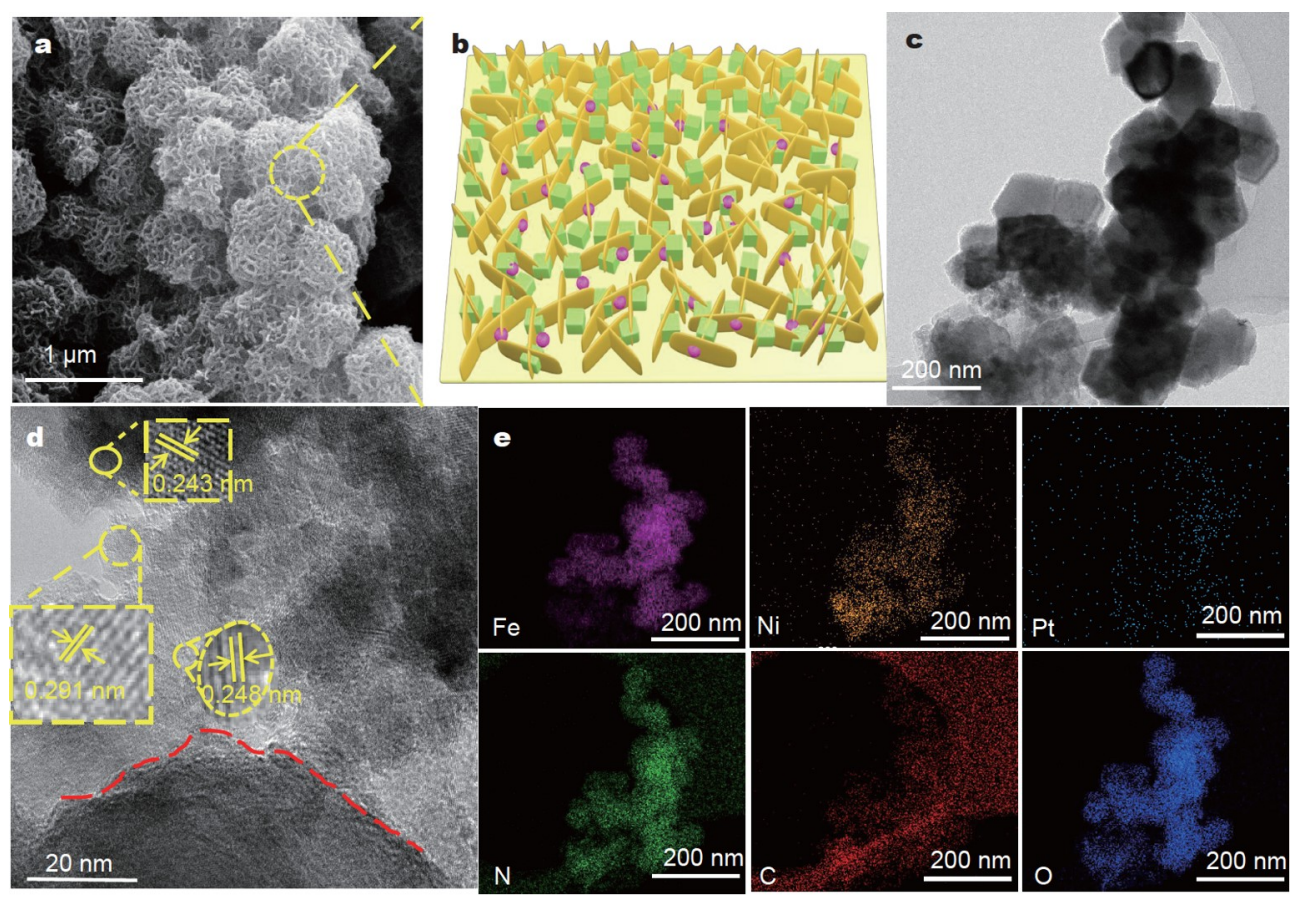

Figure 1 (a) SEM image and (b) scheme of Pt-NiFe PBA. (c) TEM image of Pt-NiFe PBA. (d) High-resolution TEM image and (e) the corresponding elemental mapping images of $\mathrm{Fe}, \mathrm{Ni}, \mathrm{Pt}, \mathrm{N}, \mathrm{C}$, and $\mathrm{O}$ in the prepared Pt-NiFe PBA. 
mizing the adsorption/adsorption of intermediates and transportation of intermediates and electrons [46]. The lamellar spacings of $0.291,0.248$, and $0.243 \mathrm{~nm}$ corresponded to $\mathrm{Fe}_{2} \mathrm{Ni}_{2}(\mathrm{CO})_{3} \mathrm{OH}_{8} \cdot 2 \mathrm{H}_{2} \mathrm{O}, \quad \mathrm{FeOOH}$, and $\mathrm{Ni}_{2}\left[\mathrm{Fe}(\mathrm{CN})_{6}\right] \cdot 0.5 \mathrm{H}_{2} \mathrm{O}$, respectively. Fig. 1e reveals the homogeneous distribution of $\mathrm{Fe}$, $\mathrm{Ni}, \mathrm{Pt}, \mathrm{N}, \mathrm{C}$, and $\mathrm{O}$ throughout the as-designed Pt-NiFe PBA.

$\mathrm{X}$-ray photoelectron spectroscopy (XPS) was performed to study the composition and chemical valence of the designed electrocatalyst. The survey spectrum verified the presence of $\mathrm{Ni}$, Fe, Pt, N, and $\mathrm{O}$ in the synthesized Pt-NiFe PBA, which is in line with the energy dispersive spectroscopy result (Fig. 2a). For high-resolution $\mathrm{Ni} 2 \mathrm{p}_{3 / 2}$ (Fig. 2b), two peaks at 856.1 and $861.4 \mathrm{eV}$ verified the existence of $\mathrm{Ni}^{2+}$ and the corresponding satellite peak, respectively [47]. As illustrated in Fig. 2c, $\mathrm{Fe}^{3+}$ $(725.1 \mathrm{eV})$ was detected in the prepared nanomaterial $[48,49]$. As for the high-resolution XPS spectrum of Pt (Fig. 2d), the diffraction peaks with binding energies of 73.6 and $76.9 \mathrm{eV}$ were ascribed to $\mathrm{Pt}^{2+}$ [50]. For $\mathrm{N} 1 \mathrm{~s}$ (Fig. S3), the typical peaks of 397.8 and $399.7 \mathrm{eV}$ were contributed by the presence of $\mathrm{C}-\mathrm{N}$ in $\mathrm{Fe}(\mathrm{CN})_{6}{ }^{4-}$ [51]. The contact angle of $\mathrm{Pt}-\mathrm{NiFe} \mathrm{PBA}$ was $0^{\circ}$, demonstrating the superhydrophilicity property, favoring the intimate contact between the electrolyte and electrode, maximizing the active surface area, and accelerating the reaction kinetics (Fig. 2e). Fig. $2 \mathrm{f}$ shows that the bubble contact angle of Pt-NiFe PBA was $120^{\circ}$, demonstrating its excellent aerophobicity. The excellent aerophobicity allows the generated hydrogen bubbles to detach from the electrode surface quickly, promoting the constant contact between active sites and the electrolyte.

Encouraged by the unique nanostructure, the electrocatalytic properties of the synthesized Pt-NiFe PBA and control samples, such as $\mathrm{NiF}, \mathrm{NiFe} \mathrm{LDH}, \mathrm{NiFe} \mathrm{PBA}$, and $\mathrm{Pt} / \mathrm{C}$, toward HER in
$1 \mathrm{~mol} \mathrm{~L}^{-1} \mathrm{KOH}$ were investigated after optimizing the parameters (Figs S4, S5). As illustrated in Fig. 3a, b, Pt-NiFe PBA exhibited a superior electrocatalytic performance toward HER with the smallest overpotentials of 29 and $58 \mathrm{mV}$ to attain 10 and $50 \mathrm{~mA} \mathrm{~cm}^{-2}$, respectively, relative to the state-of-the-art Pt/C (45, $124 \mathrm{mV})$, NiFe PBA (146, $224 \mathrm{mV})$, NiFe LDH (214, $312 \mathrm{mV})$, and $\mathrm{NiF}(267,384 \mathrm{mV})$, demonstrating the prominent catalytic activity of Pt-NiFe PBA toward HER. It also presents a high mass activity (Fig. S6). The Tafel slopes derived from polarization curves (Fig. 3c) verified the favorable reaction kinetics of Pt-NiFe PBA with the value of $58.3 \mathrm{mV} \mathrm{dec}^{-1}$, which

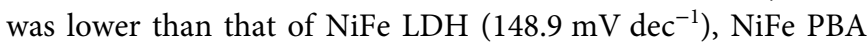

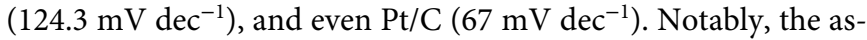
synthesized 2D/3D nanostructured Pt-NiFe PBA presents an excellent electrocatalytic performance with a small overpotential and a low Tafel slope, which are superior to some of the reported values (Fig. 3d and Table S1). Besides the electrocatalytic activity, stability is also a significant parameter to evaluate practical applications of the designed electrocatalysts. The applied voltage was extremely stable within the applied current densities, and the identical potential was obtained in the reverse process, demonstrating its excellent stability and mass transport character (Fig. 3e). Moreover, its outstanding stability was confirmed by the chronoamperometry test for $12 \mathrm{~h}$ and scanning the cyclic voltammetry (CV) for 3000 cycles (Fig. 3f and Fig. S7). Evidently, the current density was maintained well with negligible loss, further demonstrating remarkable stability of Pt-NiFe PBA. The XPS spectrum of Pt-NiFe PBA after electrocatalysis exhibited that the peak of $\mathrm{Pt} 4 \mathrm{f}$ also showed limited changes (Fig. S8), indicating the main component was still the Pt-NiFe PBA catalyst. Moreover, the designed Pt-NiFe PBA also exhibits excellent electrocatalytic performance in $1 \mathrm{~mol} \mathrm{~L}^{-1}$ phosphate
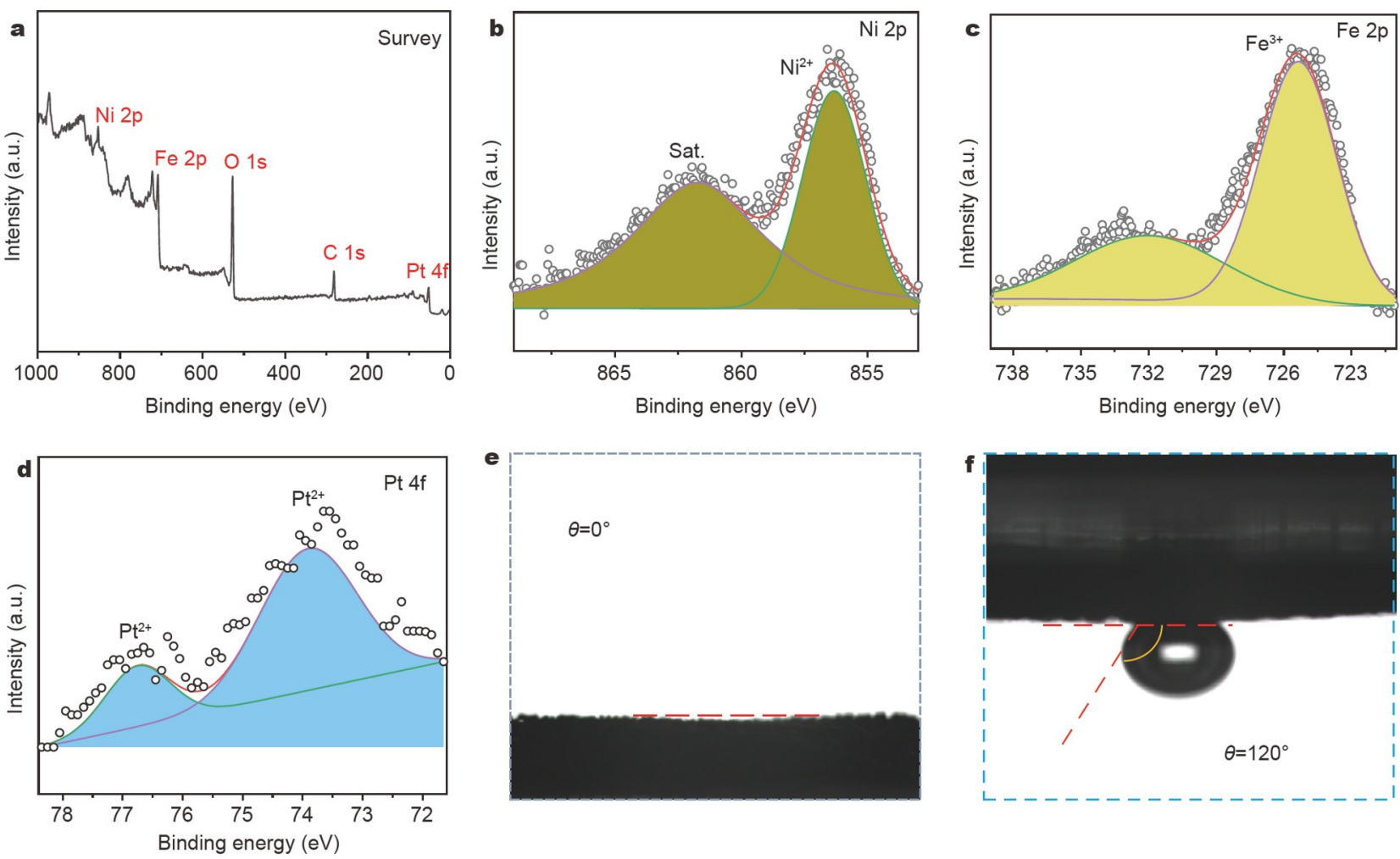

Figure 2 (a) XPS survey spectrum of the prepared Pt-NiFe PBA. High-resolution XPS spectra of (b) Ni 2p, (c) Fe 2p, and (d) Pt 4f of Pt-NiFe PBA. (e) Contact angles of Pt-NiFe PBA. (f) Bubble contact angle of Pt-NiFe PBA. 
buffer sultion (PBS) (Fig. S9).

In addition to HER, the OER activities of the prepared electrocatalysts were measured in the identical electrolyte. As illu- strated in Fig. 4a, b, the prepared Pt-NiFe PBA can drive 10 and $50 \mathrm{~mA} \mathrm{~cm}^{-2}$ current densities at the lowest overpotentials of 210 and $230 \mathrm{mV}$, respectively, which are lower than those of $\mathrm{NiF}$

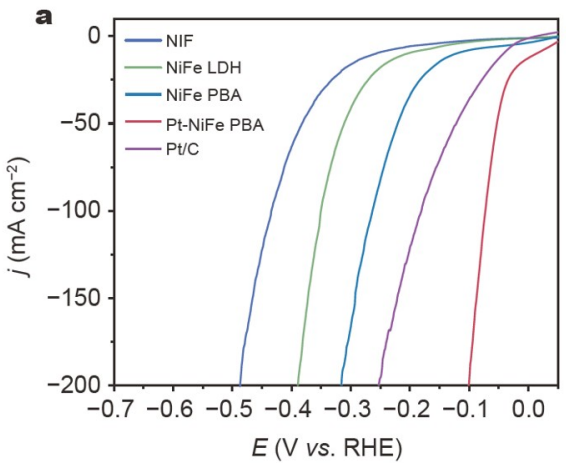

b
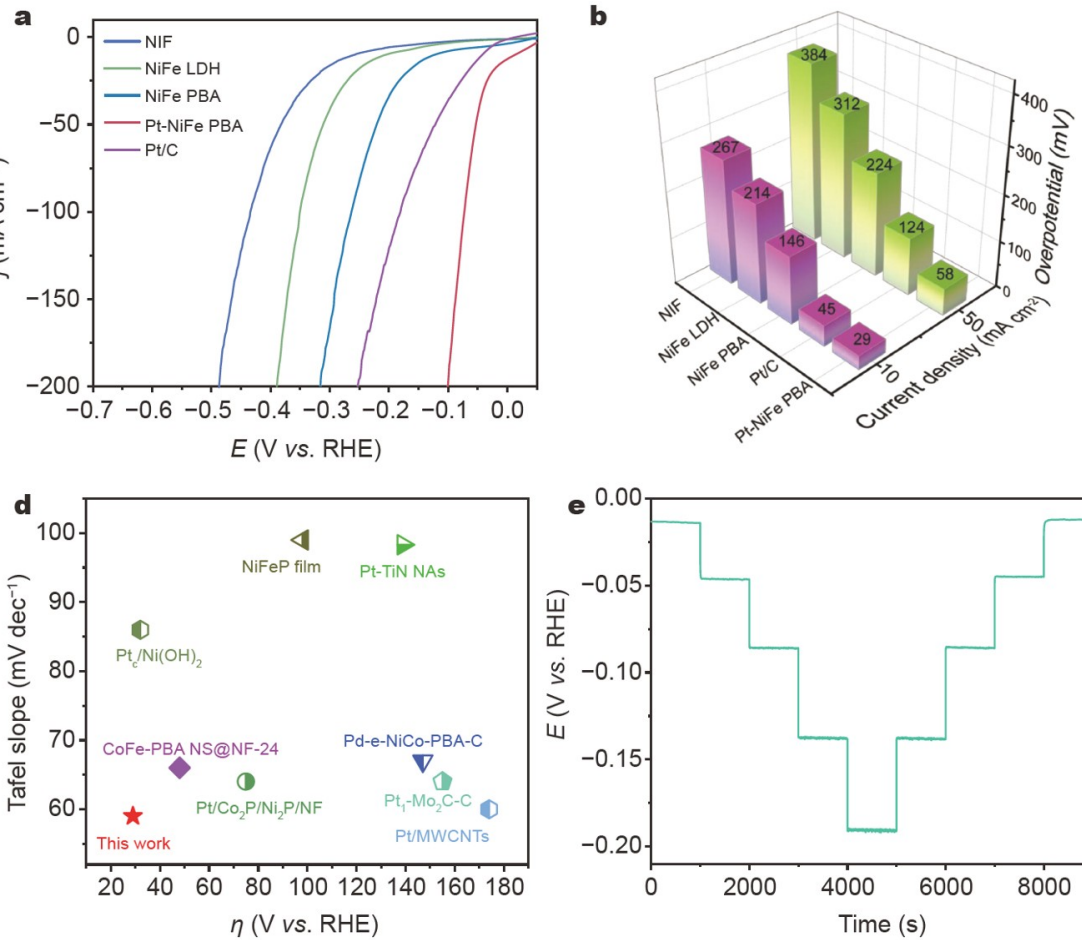
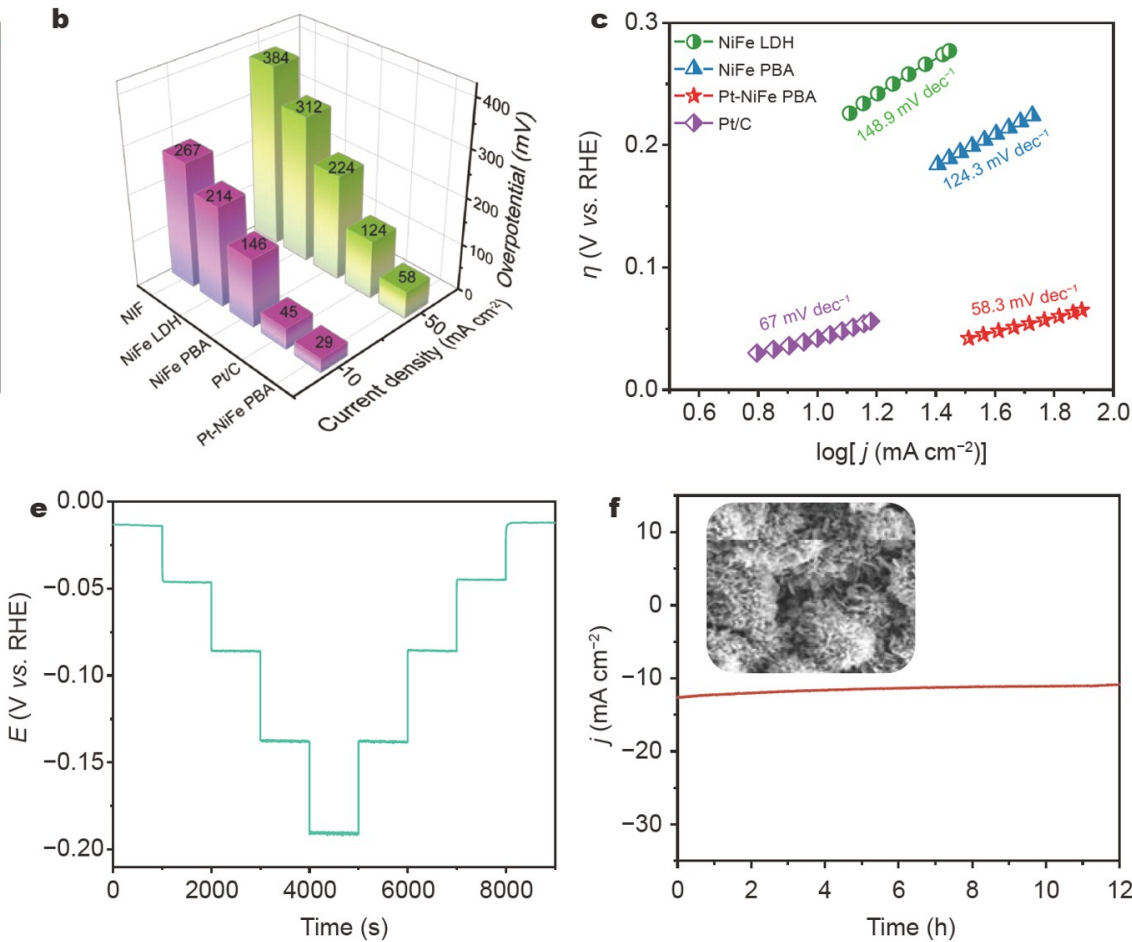

Figure 3 (a) Electrocatalytic HER properties of Pt/C, Pt-NiFe PBA, NiFe PBA, NiFe LDH, and NIF in 1 mol L ${ }^{-1}$ KOH. (b) Overpotentials at 10 and $50 \mathrm{~mA} \mathrm{~cm}^{-2}$. (c) Tafel plots of synthetic nanomaterials. (d) Comparison between Pt-NiFe PBA with the reported materials. (e) Multistep chronopotentiometric curve of Pt-NiFe PBA under different overpotentials in $1 \mathrm{~mol} \mathrm{~L}^{-1} \mathrm{KOH}$. (f) Long-term stability measurement of Pt-NiFe PBA for over $12 \mathrm{~h}$.

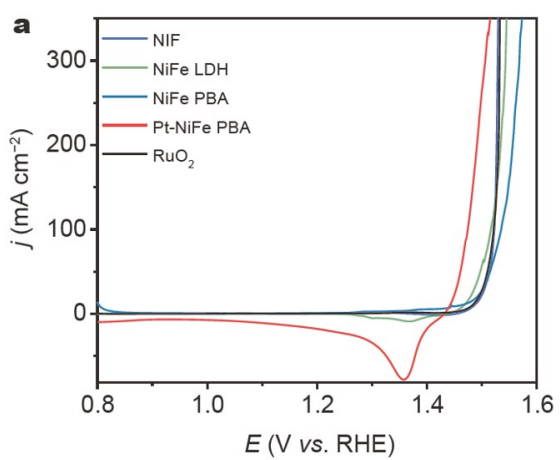

b
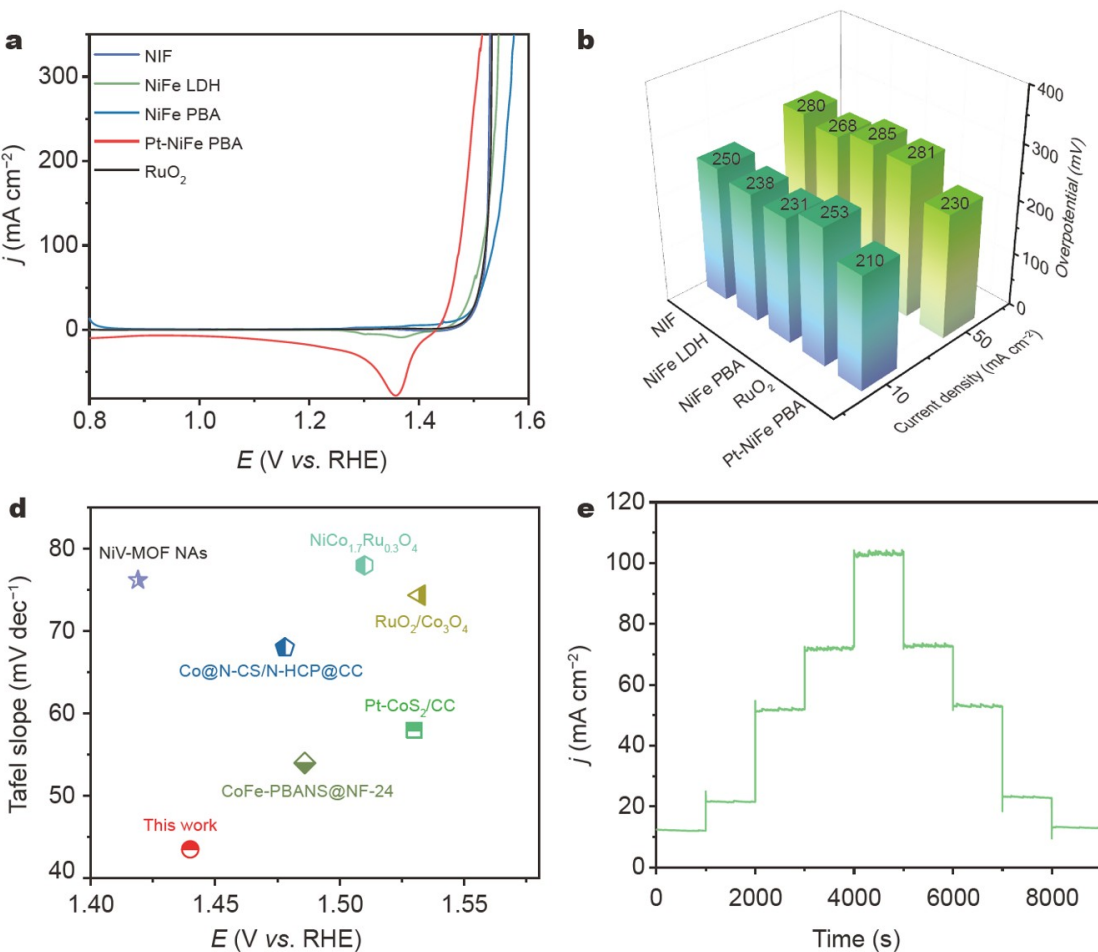
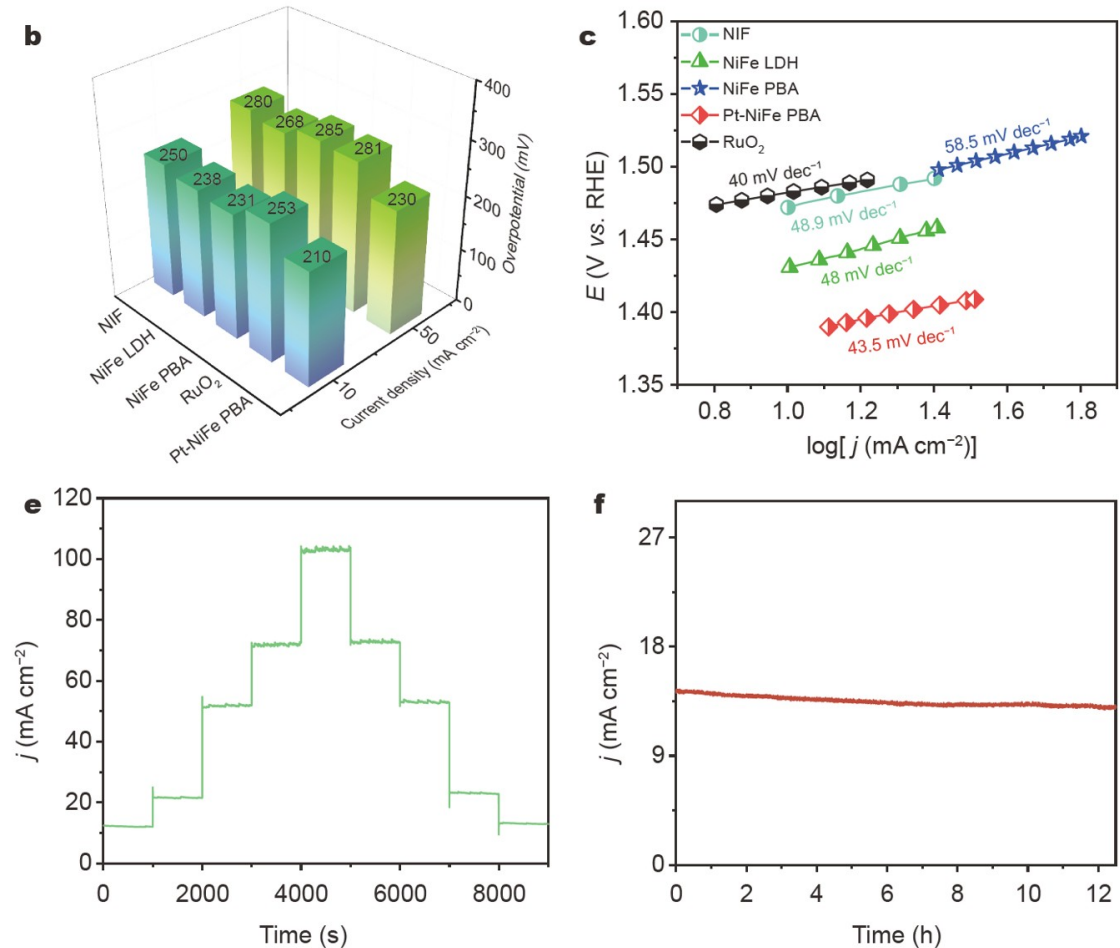

Figure 4 (a) Electrocatalytic OER properties of $\mathrm{RuO}_{2}$, Pt-NiFe PBA, NiFe PBA, NiFe LDH, and NIF in 1 mol L ${ }^{-1} \mathrm{KOH}$. (b) Overpotentials at 10 and $50 \mathrm{~mA} \mathrm{~cm}^{-2}$. (c) Tafel plots of synthetic nanomaterials. (d) Comparison between Pt-NiFe PBA with the reported materials. (e) Multistep chronoamperometric curve of Pt-NiFe PBA under different overpotentials in $1 \mathrm{~mol} \mathrm{~L}^{-1} \mathrm{KOH}$. (f) Long-term stability measurement of the Pt-NiFe PBA for over $12 \mathrm{~h}$. 
(250, $280 \mathrm{mV})$, NiFe LDH (238, $268 \mathrm{mV})$, NiFe PBA (231, $285 \mathrm{mV})$, and commercial $\mathrm{RuO}_{2}(253,281 \mathrm{mV})$. In addition, Pt$\mathrm{NiFe}$ PBA owned the most favorable reaction kinetics toward OER with the smallest Tafel slope (Fig. 4c) of $43.5 \mathrm{mV} \mathrm{dec}{ }^{-1}$ among the studied electrocatalysts. The electrocatalytic activity of the designed Pt-NiFe PBA was superior to several recently reported results (Fig. $4 \mathrm{~d}$ and Table S2). Apart from the excellent OER activity, the as-synthesized Pt-NiFe PBA owned remarkable stability. As illustrated in Fig. 4e, the current densities increased rapidly, and the same current densities were obtained in the reverse process, demonstrating the rapid charge/mass transport and stability of the Pt-NiFe PBA. Moreover, the long-term sta- bility of the prepared 2D-3D nanostructured electrocatalyst was verified by galvanostatic measurement for $12 \mathrm{~h}$ (Fig. 4f). The current density presented negligible degradation, demonstrating its remarkable stability.

Encouraged by the excellent electrocatalytic performances of Pt-NiFe PBA toward HER and OER in alkaline electrolyte, we constructed a two-electrode setup for overall water splitting with the 2D-3D nanostructured electrocatalysts as the anode and cathode (Fig. 5a). The Pt-NiFe PBA || $\mathrm{Pt}-\mathrm{NiFe} \mathrm{PBA}$ couple can afford a current density of $10 \mathrm{~mA} \mathrm{~cm}^{-2}$ at a small potential of $1.46 \mathrm{~V}$, which is lower than that of the state-of-the-art $\mathrm{Pt} / \mathrm{C} \|$ $\mathrm{RuO}_{2}(1.57 \mathrm{~V})$ and several recently published electrocatalysts
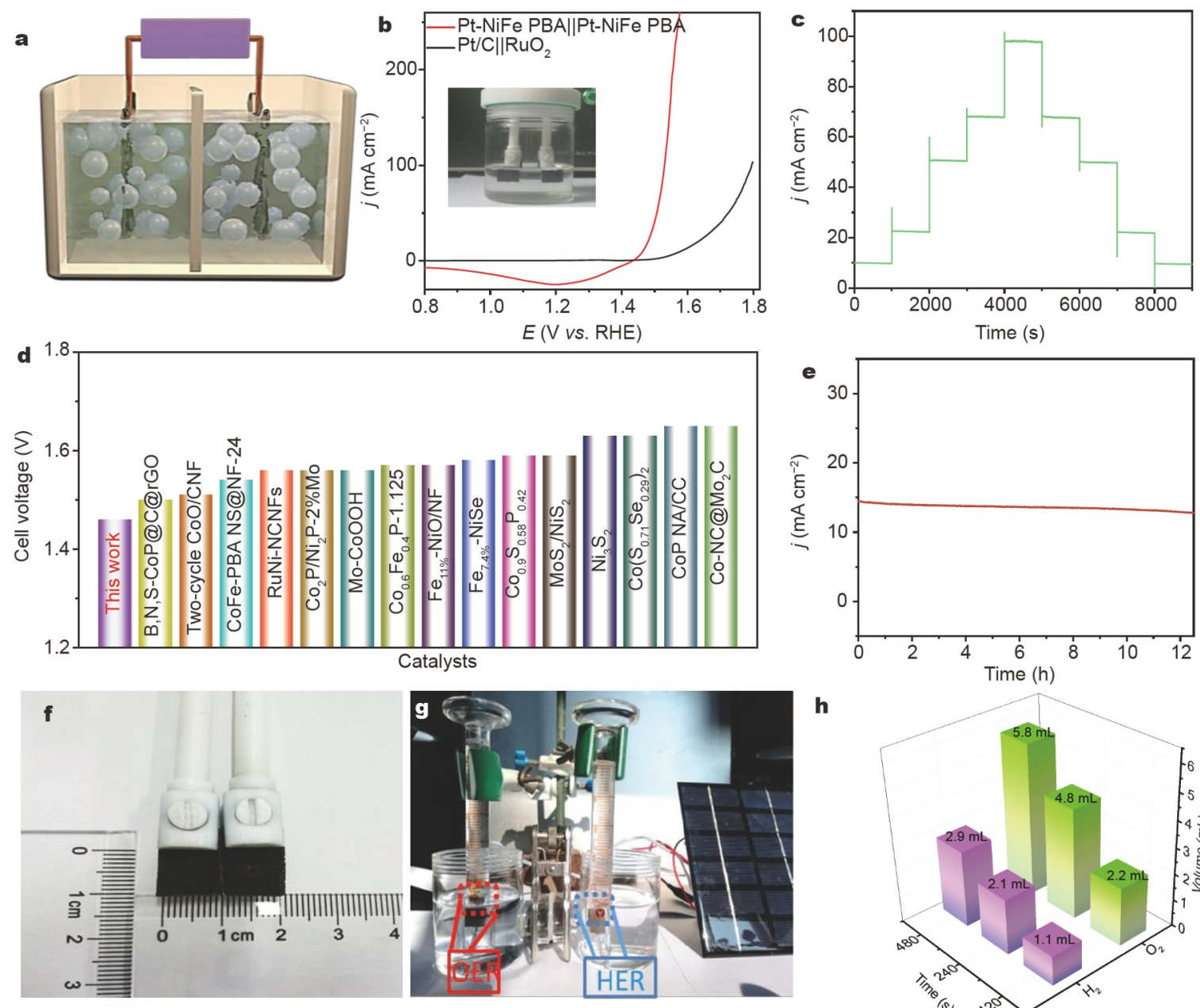

h
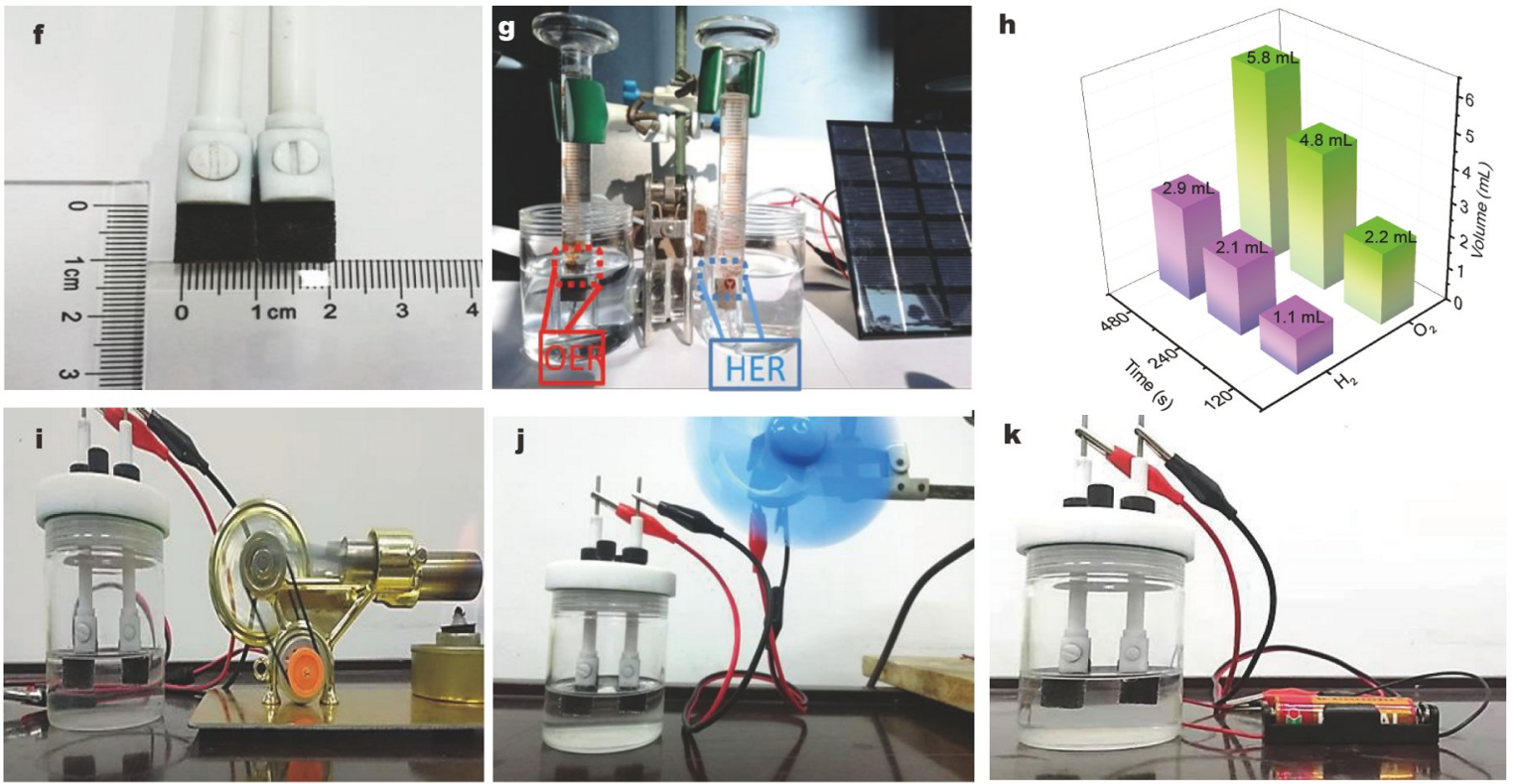

Figure 5 (a) Two-electrode water splitting configuration. (b) Polarization curves of $\mathrm{Pt} / \mathrm{C} \| \mathrm{RuO}_{2}$ toward overall water splitting in $1 \mathrm{~mol} \mathrm{~L} \mathrm{~L}^{-1} \mathrm{KOH}$. (c) Multistep chronoamperometric curve of Pt-NiFe PBA||Pt-NiFe PBA. (d) Comparison between Pt-NiFe PBA with the reported materials. (e) Long-term stability measurement of Pt-NiFe PBA||Pt-NiFe PBA for over $12 \mathrm{~h}$. (f) Image of the working electrodes. (g) Gas collection device of water splitting in 1 mol L ${ }^{-1}$ $\mathrm{KOH}$. (h) Amount of $\mathrm{H}_{2} / \mathrm{O}_{2}$ (time-dependent experimentally measured values) versus time for Pt-NiFe PBA||Pt-NiFe PBA. Schematic of overall water splitting electrocatalyzed with the electric energy generated by (i) wind, (j) Stirling engine, and (k) battery. 
(Fig. 5b, d and Table S3). Moreover, the multistep chronoamperometric response and galvanostatic measurement demonstrated the excellent stability of the as-synthesized Pt$\mathrm{NiFe}$ PBA (Fig. 5c, e). At present, sustainable energies, such as solar, wind, and thermal energies, are attracting tremendous attention due to their abundant, sustainable, and eco-friendly properties. However, the intermittent, unstable, and regional disadvantages hinder their practical applications. Intermittent energies can be stored as portable hydrogen energy through electrochemical water splitting with a working electrode. We first investigated the electrochemical overall water splitting using the designed in-situ electrocatalysts with solar energy as the power source. Notable amounts of gases were generated on the separated electrodes (Fig. 5f, $g$ and Movie S1), and they can be quantified by the drainage method. A total of 2.9 and $5.8 \mathrm{~mL}$ hydrogen and oxygen were generated in $1 \mathrm{~mol} \mathrm{~L}^{-1} \mathrm{KOH}$ within $8 \mathrm{~min}$, respectively, and the ratio of $\mathrm{H}_{2}$ and $\mathrm{O}_{2}$ was $2: 1$, demonstrating the Faraday efficiency of $100 \%$ of the prepared Pt-NiFe PBA for overall water splitting (Fig. S10a, b and Fig. 5h). Furthermore, the overall water splitting can be actuated by thermal (Fig. 5i and Movie S2) and wind energies with sumless bubbles generated (Fig. 5j and Movie S3). Large amounts of bubbles were produced using an AAA battery $(1.5 \mathrm{~V})$ as the energy source (Fig. 5k and Movie S4), demonstrating the remarkable electrocatalytic performance of the prepared $\mathrm{Pt}-\mathrm{NiFe}$ PBA $\|$ Pt-NiFe PBA electrolyzer. As discussed above, the asdesigned Pt-NiFe PBA exhibited outstanding electrocatalytic performances toward HER and OER, which can be ascribed to the following aspects: the specific 2D-3D nanostructure with rich channels and pores can expose abundant active sites for electrocatalytic reactions; the coupling effects of the metal hydroxide and MOF play pivotal roles in optimizing the reaction kinetics; the introduced trace Pt accelerated the reaction rate of HER; the binder-free property avoided the blocking of active sites and lowered the electrical resistance; the hydrophilic/ aerophobic surface favored the contact of electrolyte and the timely release of the produced gas bubbles and expedited mass transport during the electrocatalytic process.

As discussed above, the as-prepared $\mathrm{Pt}-\mathrm{NiFe} \mathrm{PBA}$ presented excellent electrocatalytic activities toward overall water splitting in $1 \mathrm{~mol} \mathrm{~L}^{-1} \mathrm{KOH}$ with deionized water. However, freshwater is a scarce resource in numerous regions over the world and limits the large-scale practical applications of water electrolysis toward hydrogen generation. Relatively, seawater splitting is a meaningful avenue for hydrogen production owing to its enormous storage on the earth. Therefore, we evaluated the electrocatalytic performance of the as-synthesized Pt-NiFe PBA in $1 \mathrm{~mol} \mathrm{~L}^{-1}$ $\mathrm{KOH}$ with seawater. As shown in Fig. 6a, b, the developed 2D$3 \mathrm{D}$ nanostructured $\mathrm{Pt}-\mathrm{NiFe} \mathrm{PBA}$ possessed excellent electrocatalytic performance toward HER with the smallest overpotentials of 21 and $47 \mathrm{mV}$ to attain 10 and $50 \mathrm{~mA} \mathrm{~cm}^{-2}$ current densities, relative to the reference samples, respectively. Moreover, the prepared Pt-NiFe PBA exhibited the lowest overpotentials in $1 \mathrm{~mol} \mathrm{~L}^{-1} \mathrm{KOH}$ with seawater toward OER $\left(250 \mathrm{mV}\right.$ at $10 \mathrm{~mA} \mathrm{~cm}^{-2}$ and $280 \mathrm{mV}$ at $50 \mathrm{~mA} \mathrm{~cm}^{-2}$ ) compared with NIF $\left(370 \mathrm{mV}\right.$ at $10 \mathrm{~mA} \mathrm{~cm}^{-2}$ and $480 \mathrm{mV}$ at $\left.50 \mathrm{~mA} \mathrm{~cm}^{-2}\right)$, $\mathrm{NiFe} \mathrm{LDH}\left(273 \mathrm{mV}\right.$ at $10 \mathrm{~mA} \mathrm{~cm}^{-2}$ and $310 \mathrm{mV}$ at $\left.50 \mathrm{~mA} \mathrm{~cm}^{-2}\right)$, NiFe PBA $\left(290 \mathrm{mV}\right.$ at $10 \mathrm{~mA} \mathrm{~cm}^{-2}$ and $340 \mathrm{mV}$ at $\left.50 \mathrm{~mA} \mathrm{~cm}^{-2}\right)$, and $\mathrm{RuO}_{2}\left(300 \mathrm{mV}\right.$ at $10 \mathrm{~mA} \mathrm{~cm}^{-2}$ and $360 \mathrm{mV}$ at $50 \mathrm{~mA} \mathrm{~cm}^{-2}$ ) (Fig. $6 \mathrm{c}, \mathrm{d}$ ), demonstrating its excellent electrocatalytic activity. Given the outstanding electrocatalytic performances of the designed Pt-NiFe PBA for HER and OER, we further studied the overall seawater splitting using a two-electrode electrolyzer with the as-synthesized Pt-NiFe PBA as the
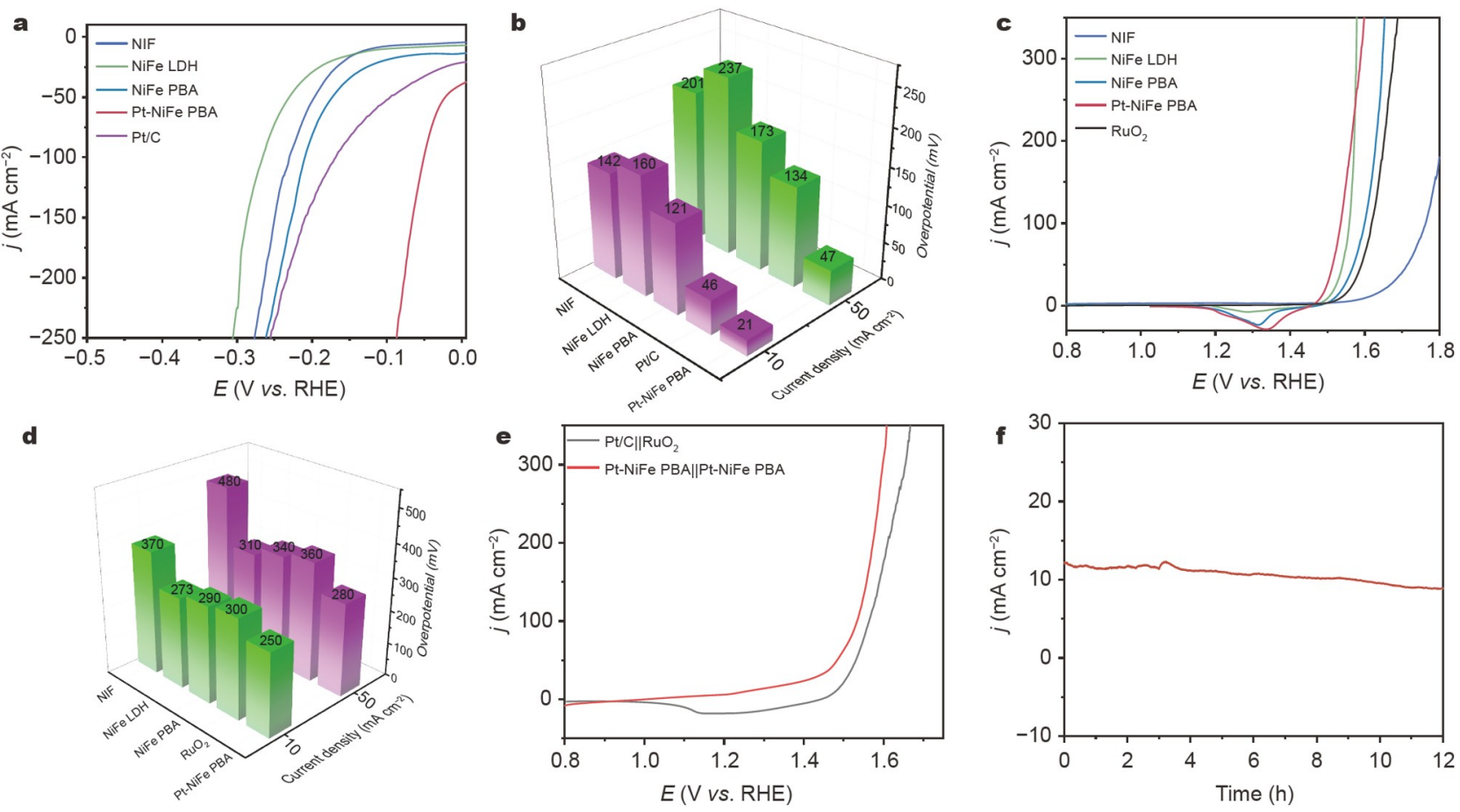

Figure 6 (a) Electrocatalytic HER properties of Pt/C, Pt-NiFe PBA, NiFe PBA, NiFe LDH, and NIF in 1 mol L ${ }^{-1} \mathrm{KOH}$ with seawater. (b) Overpotentials for HER at 10 and $50 \mathrm{~mA} \mathrm{~cm}^{-2}$. (c) Electrocatalytic OER properties of $\mathrm{RuO}_{2}, \mathrm{Pt}-\mathrm{NiFe} \mathrm{PBA}, \mathrm{NiFe} \mathrm{PBA}, \mathrm{NiFe} \mathrm{LDH}$, and NIF in 1 mol L $\mathrm{K}^{-1} \mathrm{KOH}$ with seawater. (d) Overpotentials for OER at 10 and $50 \mathrm{~mA} \mathrm{~cm}^{-2}$. (e) Polarization curves of $\mathrm{Pt} / \mathrm{C} \| \mathrm{RuO}_{2}$ and Pt-NiFe PBA $\mid \mathrm{Pt}-\mathrm{NiFe} \mathrm{PBA}$ toward overall water splitting in

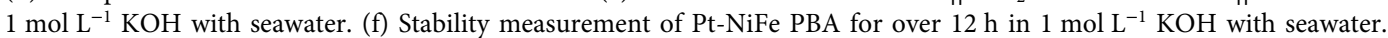


anode and cathode. Remarkably, the electrolyzer showed an excellent electrocatalytic seawater splitting activity in alkaline seawater electrolytes. As displayed in Fig. 6e, low overpotentials of 1.48 and $1.56 \mathrm{~V}$ were needed to reach 10 and $100 \mathrm{~mA} \mathrm{~cm}^{-2}$ current densities of the designed electrocatalyst, respectively, which were superior to those of $\mathrm{Pt} / \mathrm{C} \| \mathrm{RuO}_{2}$. More importantly, the current density was maintained well for $12 \mathrm{~h}$ in seawater electrolyte, verifying the superior stability of the two-electrode electrolyzer (Fig. 6f).

\section{CONCLUSIONS}

In summary, a novel 2D-3D hybrid loaded with trace Pt was developed by the combination of corrosive and coordinate engineering. The obtained Pt-NiFe PBA presented outstanding electrocatalytic performances toward HER, OER, and overall water splitting with excellent long-term stability in $1 \mathrm{~mol} \mathrm{~L}^{-1}$ $\mathrm{KOH}$ with deionized water and alkaline seawater. Remarkably, we utilized sustainable solar, wind, and thermal energies to drive the overall water splitting and then stored them as green and sustainable hydrogen gas energy. The excellent electrocatalytic activity can be ascribed to the designed specific nanostructure, binder-free feature, coupling effects, and hydrophilicity/aerophobicity features, resulting in the abundant exposed active sites, favorable mass/charge transport, and optimized reaction kinetics. The synthetic approach presented in this work provides valuable directions for the development of other specific nanostructures via corrosive engineering for electrochemical energy storage and conversion fields.

\section{Received 18 November 2021; accepted 21 December 2021; published online 30 December 2021}

1 Jing $\mathrm{H}$, Zhu $\mathrm{P}$, Zheng $\mathrm{X}$, et al. Theory-oriented screening and discovery of advanced energy transformation materials in electrocatalysis. Adv Powder Mater, 2021, doi: 10.1016/j.apmate.2021.10.004

2 Fang W, Huang L, Zaman S, et al. Recent progress on two-dimensional electrocatalysis. Chem Res Chin Univ, 2020, 36: 611-621

3 Liu Y, Feng Q, Liu W, et al. Boosting interfacial charge transfer for alkaline hydrogen evolution via rational interior Se modification. Nano Energy, 2021, 81: 105641

4 Gong L, Yang H, Wang H, et al. Corrosion formation and phase transformation of nickel-iron hydroxide nanosheets array for efficient water oxidation. Nano Res, 2021, 14: 4528-4533

5 Pan Y, Zhang C, Lin Y, et al. Electrocatalyst engineering and structureactivity relationship in hydrogen evolution reaction: From nanostructures to single atoms. Sci China Mater, 2020, 63: 921-948

6 Wang TJ, Sun HY, Xue Q, et al. Holey platinum nanotubes for ethanol electrochemical reforming in aqueous solution. Sci Bull, 2021, 66: 2079-2089

7 Shan J, Ye C, Chen S, et al. Short-range ordered iridium single atoms integrated into cobalt oxide spinel structure for highly efficient electrocatalytic water oxidation. J Am Chem Soc, 2021, 143: 5201-5211

8 Zheng F, Zhang W, Zhang X, et al. Sub-2 nm ultrathin and robust 2D FeNi layered double hydroxide nanosheets packed with 1D FeNi-MOFs for enhanced oxygen evolution electrocatalysis. Adv Funct Mater, 2021, 31: 2103318

$9 \mathrm{Yu} \mathrm{W}$, Gao Y, Chen Z, et al. Strategies on improving the electrocatalytic hydrogen evolution performances of metal phosphides. Chin J Catal, 2021, 42: 1876-1902

10 Benck JD, Hellstern TR, Kibsgaard J, et al. Catalyzing the hydrogen evolution reaction (HER) with molybdenum sulfide nanomaterials. ACS Catal, 2014, 4: 3957-3971

11 Mahmood J, Li F, Jung SM, et al. An efficient and pH-universal ruthenium-based catalyst for the hydrogen evolution reaction. Nat Nanotech, 2017, 12: 441-446
12 Popczun EJ, Read CG, Roske CW, et al. Highly active electrocatalysis of the hydrogen evolution reaction by cobalt phosphide nanoparticles. Angew Chem Int Ed, 2014, 53: 5427-5430

13 Zhou W, Wu M, Li G. Rambutan-like CoP@Mo-Co-O hollow microspheres for efficient hydrogen evolution reaction in alkaline solution. Chin J Catal, 2020, 41: 691-697

14 Jin $\mathrm{H}, \mathrm{Gu} \mathrm{Q}$, Chen B, et al. Molten salt-directed catalytic synthesis of 2D layered transition-metal nitrides for efficient hydrogen evolution. Chem, 2020, 6: 2382-2394

15 Yang J, Li W, Wang D, et al. Electronic metal-support interaction of single-atom catalysts and applications in electrocatalysis. Adv Mater, 2020, 32: 2003300

16 Chen Q, Nie Y, Ming M, et al. Sustainable synthesis of supported metal nanocatalysts for electrochemical hydrogen evolution. Chin J Catal, 2020, 41: 1791-1811

$17 \mathrm{Wu} \mathrm{Z}$, Zhao $\mathrm{Y}, \mathrm{Wu} \mathrm{H}$, et al. Corrosion engineering on iron foam toward efficiently electrocatalytic overall water splitting powered by sustainable energy. Adv Funct Mater, 2021, 31: 2010437

$18 \mathrm{Yu} \mathrm{X}$, Chen G, Wang Y, et al. Hierarchical coupling effect in hollow Ni/ $\mathrm{NiFe}_{2} \mathrm{O}_{4}$-CNTs microsphere via spray-drying for enhanced oxygen evolution electrocatalysis. Nano Res, 2020, 13: 437-446

19 Xue Q, Bai XY, Zhao Y, et al. Au core-PtAu alloy shell nanowires for formic acid electrolysis. J Energy Chem, 2022, 65: 94-102

20 Wang J, Zhang Z, Song H, et al. Water dissociation kinetic-oriented design of nickel sulfides via tailored dual sites for efficient alkaline hydrogen evolution. Adv Funct Mater, 2021, 31: 2008578

21 Zhang $\mathrm{X}$, Zhao $\mathrm{Y}$, Zhao $\mathrm{Y}$, et al. A simple synthetic strategy toward defect-rich porous monolayer NiFe-layered double hydroxide nanosheets for efficient electrocatalytic water oxidation. Adv Energy Mater, 2019, 9: 1900881

22 Song $\mathrm{M}$, Zhang $\mathrm{Z}$, Li Q, et al. Ni-foam supported $\mathrm{Co}(\mathrm{OH}) \mathrm{F}$ and $\mathrm{Co}-\mathrm{P}$ nanoarrays for energy-efficient hydrogen production via urea electrolysis. J Mater Chem A, 2019, 7: 3697-3703

23 Cong $\mathrm{M}$, Sun $\mathrm{D}$, Zhang $\mathrm{L}$, et al. In situ assembly of metal-organic framework-derived $\mathrm{N}$-doped carbon/Co/CoP catalysts on carbon paper for water splitting in alkaline electrolytes. Chin J Catal, 2020, 41: 242248

24 Smialkowski M, Tetzlaff D, Hensgen L, et al. Fe/Co and Ni/Co-pentlandite type electrocatalysts for the hydrogen evolution reaction. Chin J Catal, 2021, 42: 1360-1369

25 Mao J, He CT, Pei J, et al. Isolated $\mathrm{Ni}$ atoms dispersed on Ru nanosheets: High-performance electrocatalysts toward hydrogen oxidation reaction. Nano Lett, 2020, 20: 3442-3448

26 Yuan Z, Bak SM, Li P, et al. Activating layered double hydroxide with multivacancies by memory effect for energy-efficient hydrogen production at neutral pH. ACS Energy Lett, 2019, 4: 1412-1418

27 Huang Y, Li M, Yang W, et al. 3D ordered mesoporous cobalt ferrite phosphides for overall water splitting. Sci China Mater, 2020, 63: 240248

28 Meng X, Ma C, Jiang L, et al. Distance synergy of $\mathrm{MoS}_{2}$-confined rhodium atoms for highly efficient hydrogen evolution. Angew Chem, 2020, 132: 10588-10593

29 Zhang L, Xiao W, Zhang Y, et al. Nanocarbon encapsulating Ni-doped $\mathrm{MoP} /$ graphene composites for highly improved electrocatalytic hydrogen evolution reaction. Compos Commun, 2021, 26: 100792

30 Li P, Duan X, Kuang Y, et al. Tuning electronic structure of $\mathrm{NiFe}$ layered double hydroxides with vanadium doping toward high efficient electrocatalytic water oxidation. Adv Energy Mater, 2018, 8: 1703341

31 Lu F, Yi D, Liu S, et al. Engineering platinum-oxygen dual catalytic sites via charge transfer towards highly efficient hydrogen evolution. Angew Chem, 2020, 132: 17865-17871

32 Wang $\mathrm{H}$, Zhang $\mathrm{X}$, Wang $\mathrm{J}$, et al. Puffing quaternary $\mathrm{Fe}_{x} \mathrm{Co}_{y} \mathrm{Ni}_{1-x-y} \mathrm{P}$ nanoarray via kinetically controlled alkaline etching for robust overall water splitting. Sci China Mater, 2020, 63: 1054-1064

33 Lv L, Yang Z, Chen $\mathrm{K}$, et al. 2D layered double hydroxides for oxygen evolution reaction: From fundamental design to application. Adv Energy Mater, 2019, 9: 1803358

34 Zhang J, Yu L, Chen Y, et al. Designed formation of double-shelled NiFe layered-double-hydroxide nanocages for efficient oxygen evolution 
reaction. Adv Mater, 2020, 32: 1906432

35

Bo X, Dastafkan K, Zhao C. Design of multi-metallic-based electrocatalysts for enhanced water oxidation. ChemPhysChem, 2019, 20: 2936-2945

36 Zhai $\mathrm{P}$, Zhang $\mathrm{Y}, \mathrm{Wu} \mathrm{Y}$, et al. Engineering active sites on hierarchical transition bimetal oxides/sulfides heterostructure array enabling robust overall water splitting. Nat Commun, 2020, 11: 5462

37 Sun F, Wang G, Ding Y, et al. NiFe-based metal-organic framework nanosheets directly supported on nickel foam acting as robust electrodes for electrochemical oxygen evolution reaction. Adv Energy Mater, 2018, 8: 1800584

38 Li Z, Wu X, Jiang $\mathrm{X}$, et al. Surface carbon layer controllable $\mathrm{Ni}_{3} \mathrm{Fe}$ particles confined in hierarchical $\mathrm{N}$-doped carbon framework boosting oxygen evolution reaction. Adv Powder Mater, 2021, doi: 10.1016/j. apmate.2021.11.007

39 Wang Y, Yan L, Dastafkan K, et al. Lattice matching growth of conductive hierarchical porous MOF/LDH heteronanotube arrays for highly efficient water oxidation. Adv Mater, 2021, 33: 2006351

40 Zhang Z, Li X, Zhong C, et al. Spontaneous synthesis of silver-nanoparticle-decorated transition-metal hydroxides for enhanced oxygen evolution reaction. Angew Chem Int Ed, 2020, 59: 7245-7250

41 Luo J, Wang XH, Shen L, et al. Corrosion-engineered Mo-containing FeCo-(oxy)hydroxide electrocatalysts for superior oxygen evolution reaction. ACS Sustain Chem Eng, 2021, 9: 12233-12241

42 Xuan C, Peng Z, Xia K, et al. Self-supported ternary Ni-Fe-P nanosheets derived from metal-organic frameworks as efficient overall water splitting electrocatalysts. Electrochim Acta, 2017, 258: 423-432

43 Yang $\mathrm{H}$, Wang $\mathrm{C}$, Zhang $\mathrm{Y}$, et al. Green synthesis of $\mathrm{NiFe} \mathrm{LDH} / \mathrm{Ni}$ foam at room temperature for highly efficient electrocatalytic oxygen evolution reaction. Sci China Mater, 2019, 62: 681-689

44 Ma Y, Wang B, Wang Q, et al. Facile synthesis of $\alpha-\mathrm{FeOOH} / \gamma-\mathrm{Fe}_{2} \mathrm{O}_{3}$ by a pH gradient method and the role of $\gamma-\mathrm{Fe}_{2} \mathrm{O}_{3}$ in $\mathrm{H}_{2} \mathrm{O}_{2}$ activation under visible light irradiation. Chem Eng J, 2018, 354: 75-84

45 Zhang G, Li Y, Xiao X, et al. In situ anchoring polymetallic phosphide nanoparticles within porous Prussian blue analogue nanocages for boosting oxygen evolution catalysis. Nano Lett, 2021, 21: 3016-3025

$46 \mathrm{Wu} \mathrm{Z}$, Guo X, Zhang Z, et al. Interface engineering of $\mathrm{MoS}_{2}$ for electrocatalytic performance optimization for hydrogen generation via urea electrolysis. ACS Sustain Chem Eng, 2019, 7: 16577-16584

47 Hao S, Chen L, Yu C, et al. NiCoMo hydroxide nanosheet arrays synthesized via chloride corrosion for overall water splitting. ACS Energy Lett, 2019, 4: 952-959

48 Liu X, Guo X, Gong M, et al. Corrosion-assisted large-scale production of hierarchical iron rusts/ $\mathrm{Ni}(\mathrm{OH})_{2}$ nanosheet-on-microsphere arrays for efficient electrocatalysis. Electrochim Acta, 2020, 353: 136478

49 Wang K, Du H, He S, et al. Kinetically controlled, scalable synthesis of $\gamma$-FeOOH nanosheet arrays on nickel foam toward efficient oxygen evolution: The key role of in-situ-generated $\gamma-\mathrm{NiOOH}$. Adv Mater, 2021, 33: 2005587

50 Song P, Feng JJ, Zhong SX, et al. Facile preparation of reduced graphene oxide supported PtNi alloyed nanosnowflakes with high catalytic activity. RSC Adv, 2015, 5: 35551-35557

51 Gao ZD, Han YY, Li YC, et al. Photocatalytic synthesis and synergistic effect of Prussian blue-decorated Au nanoparticles/ $/ \mathrm{TiO}_{2}$ nanotube arrays for $\mathrm{H}_{2} \mathrm{O}_{2}$ amperometric sensing. Electrochim Acta, 2014, 125: 530535

Acknowledgements The authors acknowledge the support from the National Natural Science Foundation of China (22002068, 51772162 and 52072197), the Youth Innovation and Technology Foundation of Shandong Higher Education Institutions, China (2019KJC004), the Outstanding Youth Foundation of Shandong Province (ZR2019JQ14), Taishan Scholar Young Talent Program (tsqn201909114), the Major Scientific and Technological Innovation Project (2019JZZY020405), the Major Basic Research Program of Natural Science Foundation of Shandong Province (ZR2020ZD09), China Postdoctoral Science Foundation (2021M691700), the Natural Science Foundation of Shandong Province of China (ZR2019BB002, ZR2018BB031), Australian Research Future Fellowship (FT210100298), CSIRO Energy
Centre, and the Victorian Government's support through the provision of a grant from Veski-Study Melbourne Research Partnerships Project.

Author contributions Chen $\mathrm{Z}$ performed the experiments and wrote the paper with support from $\mathrm{Wu} \mathrm{Z}$ and Wang L. All authors contributed to the general discussion.

Conflict of interest The authors declare no conflict of interest.

Supplementary information Experimental details and supporting data are available in the online version of the paper.

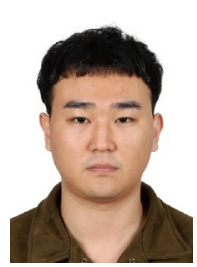

Zhi Chen graduated from Zaozhuang University in 2019. $\mathrm{He}$ is currently studying at the School of Chemistry and Molecular Engineering, Qingdao University of Science and Technology (QUST), under Dr. Zexing Wu. His current research interest is the design and synthesis of high-efficiency electrocatalysts for overall water splitting.

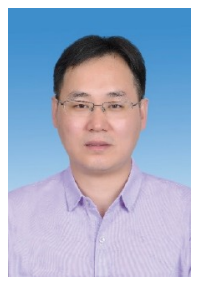

Lei Wang received his $\mathrm{PhD}$ degree in 2006 from Jilin University. Afterward, he joined the Faculty of QUST, where he was the deputy director of the Key Laboratory of Eco-Chemical Engineering. Now he is the director of the College of Environment and Safety Engineering. From 2008 to 2010, he worked as a postdoctoral fellow in the State Key Laboratory of Crystal Materials, Shandong University. His research interests currently focus on the design and synthesis of porous MOF materials, functional inorganic materials, and their applications in gas separation, photocatalysis, lithium-ion battery, etc.

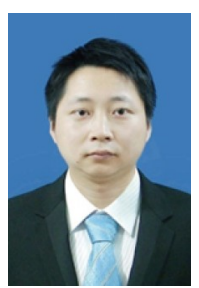

Zexing Wu is currently working at the School of Chemistry and Molecular Engineering, QUST. He received his BSc from Binzhou University, and $\mathrm{PhD}$ from Huazhong University of Science \& Technology. His research mainly focuses on the design and fabrication of nanomaterials with high performance in energy storage and conversion devices.

\section{腐蚀-配位工程构建含有微量Pt的2D-3D纳米结构高 效电解水催化剂}

陈智 ${ }^{1}$, 刘东政 ${ }^{1}$, 高玉肖 ${ }^{1}$, 赵堂 ${ }^{1}$, 肖卫平 ${ }^{2}$, 徐广荵 $^{1}$, 马天翼 ${ }^{3}$, 吴则星 ${ }^{1 *}$, 王磊 ${ }^{*}$

摘要 开发具有良好的催化性能和稳定性的析氢反应(HER)和析氧反 应(OER)的电催化剂对水分解产氢的商业化起着关键作用. 本文通过简 单、可扩展的腐蚀配位方法, 将金属氢氧化物和金属有机骨架 (MOF) 组成的二维-三维 (2D-3D) 纳米结构原位装饰在泡沫 $\mathrm{NiFe}$ (Pt-NiFe $\mathrm{PBA})$ 上. 所设计的特殊形态有利于在电催化过程中提供丰富的活性位 点、优化反应途径和加速传质. 因此, 合成的 Pt-NiFe PBA在 $1 \mathrm{~mol} \mathrm{~L}^{-1}$ KOH中HER和OER 在 $10 \mathrm{~mA} \mathrm{~cm}{ }^{-2}$ 时具有 29 和 $210 \mathrm{mV}$ 的过电位. 值得注 意的是, 在 $10 \mathrm{~mA} \mathrm{~cm}^{-2}$ 时该催化剂仅需 $21 \mathrm{mV}$ 即可驱动 $1 \mathrm{~mol} \mathrm{~L}^{-1} \mathrm{KOH}$ 海水, 并具有出色的稳定性. 此外, 将合成的 Pt-NiFe PBA用作双功能电 催化剂时, 只需 1.46 和 $1.48 \mathrm{~V}$ 即可以达到 $10 \mathrm{~mA} \mathrm{~cm}^{-2}$. 此外, 间歇性的可 持续能源, 如热能、风能和太阳能可以为该水分解器提供动力. 